\title{
Efetividade de uma iniciativa de manejo para contenção da exploração florestal ilegal em um Projeto de Desenvolvimento Sustentável em Anapu, Pará Effectiveness of a forest management initiative to contain illegal logging in a Sustainable Development Project in Anapu, Pará
}

\author{
Igor da Silva Narvaes' (1) | Roberto Porro" (1) | Tássio Franco Cordeiro"ll (1)

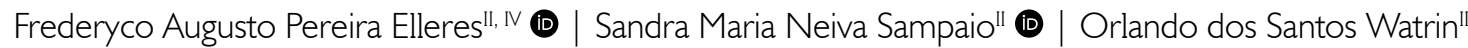 \\ Instituto Nacional de Pesquisas Espaciais. Coordenação Espacial do Sul. Santa Maria, Rio Grande do Sul, Brasil \\ "Empresa Brasileira de Pesquisa Agropecuária-Amazônia Oriental. Belém, Pará, Brasil \\ "'Universidade Federal de Viçosa. Viçosa, Minas Gerais, Brasil \\ Iv Universidade Federal Rural da Amazônia. Belém, Pará, Brasil
}

\begin{abstract}
Resumo: A pressão por áreas florestais a serem exploradas é constante na Amazônia. Projetos de Desenvolvimento Sustentável (PDS) constituem uma modalidade de assentamento rural com objetivos sociais e ambientais, tendo o manejo florestal sustentável como alternativa para geração de renda. Utilizando a metodologia de "Detecção de exploração madeireira em tempo quase real" (DETEX), desenvolvida pelo Instituto Nacional de Pesquisas Espaciais (INPE), este estudo analisou a ocorrência de exploração florestal licenciada e não autorizada no PDS Virola-Jatobá (PDS-VJ), município de Anapu, Pará, no período de 1999 a 2016. Foram identificadas alterações não autorizadas em 18.519 ha, sendo que $92 \%$ desta alteração ocorreram anteriormente a 2004, quando houve o assentamento das famílias, e outros 4,9\% ocorreram quando o plano de manejo conduzido pela associação local não havia iniciado ou estava interrompido. Os resultados comprovam a assertividade das técnicas utilizadas, embora limitadas pela resolução espacial das imagens Landsat. O PDS-VJ, apesar de ainda não ter sido eficaz na consolidação de meios de vida sustentáveis, tem no manejo florestal uma alternativa que se mostrou promissora na contenção da exploração florestal não autorizada, pois apenas 3,1\% das alterações ilegais observadas ao longo de 18 anos ocorreram durante sua vigência.
\end{abstract}

Palavras-chave: Amazônia. Assentamento de reforma agrária. Manejo florestal comunitário. Geotecnologias. Análise multitemporal. Projeto DETEX.

\begin{abstract}
The pressure for forest areas to be explored is constant in the Amazon. Sustainable Development Projects (PDS) constitute a rural settlement modality with social and environmental objectives, with sustainable forest management as an alternative for income generation. Using the DETEX methodology (Near Real-Time Logging Detection), developed by Brazil's National Institute for Space Research, this study analyzed the occurrence of licensed and unauthorized logging at PDS Virola-Jatobá, in the Anapu municipality, state of Pará. Unauthorized logging in the 1999-2016 period was identified in 18.519 ha, $92 \%$ of which occurred prior to 2004, when families were settled, and other $4.9 \%$ when the forest management plan conducted by the local association had not started or was interrupted. Results confirm the accuracy of the techniques used, although limited by Landsat images' spatial resolution. Although the Virola-Jatobá PDS has not yet been effective in consolidating sustainable livelihoods, forest management proved to be a promising alternative in curbing unauthorized timber extraction, as only $3.1 \%$ of the illegal logging observed over 18 years occurred during its existence.
\end{abstract}

Keywords: Amazon. Land reform settlement. Community forest management. Geotecnologies. Multiteporal analysis. DETEX Project.

NARVAES, I. S., R. PORRO, T. F. CORDEIRO, F. A. P. ELLERES, S. M. N. SAMPAIO \& O. S. WATRIN, 2021. Efetividade de uma iniciativa de manejo para contenção da exploração florestal ilegal em um Projeto de Desenvolvimento Sustentável em Anapu, Pará. Boletim do Museu Paraense Emílio Goeldi. Ciências Naturais 16(1): 97-114. DOI: http://doi.org/10.46357/bcnaturais.v16i1.320.

Autor para correspondência: Igor da Silva Narvaes. Coordenação Espacial do Sul - COESU. Campus da Universidade. Caixa Postal nº 5021. Santa Maria, RS, Brasil. CEP 97105-970 (igor.narvaes@inpe.br).

Recebido em 20/06/2020

Aprovado em 07/12/2020

Responsabilidade editorial: José Nazareno Araújo dos Santos Junior

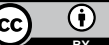




\section{INTRODUÇÃO}

A pressão por áreas a serem exploradas economicamente é uma constante na Amazônia brasileira, principalmente após os planos de desenvolvimento elaborados pelo governo federal para esta região, a partir da década de 1960, quando surgiu o termo Amazônia Legal (Marques, 2013). Tais planos preconizam instalação de infraestrutura viária, bem como projetos agropecuários e de mineração, com a justificativa de "ocupar para não entregar", sob a ótica dos governos militares e posteriormente civis que implementaram políticas públicas voltadas para a integração da Amazônia às regiões do país (Franchi et al., 2011), cujo desenvolvimento econômico era considerado mais dinâmico. Seus objetivos incluíam aumentar a capacidade de produção energética e agropecuária, além de prover infraestrutura para escoamento desta produção (Kohlhepp, 2002), porém isso foi feito desconsiderando-se a dimensão ambiental como premissa para o desenvolvimento sustentável (Abers et al., 2017; Moran, 2016).

Tais programas e políticas pretéritasforam aperfeiçoados, do ponto de vista social e ambiental (Azevedo-Ramos, 2008), principalmente após a implementação, em 2004, do Plano de Ação para Prevenção e Controle do Desmatamento na Amazônia Legal (PPCDAm) (Ramos, 2020). Embora ainda persista a concentração de renda e da terra, potencializando conflitos fundiários e o consequente aumento da violência (Chimeli \& Soares, 2017), ações no âmbito do PPCDAm apresentam inegável relação com a redução das taxas de desmatamento na Amazônia Legal (Arima et al., 2014; Mello \& Artaxo, 2017), mais expressivas nos estados do Mato Grosso e do Pará (Börner et al., 2015), intimamente ligadas a atividades de exploração florestal, em sua maioria ilegal (Asner et al., 2006, 2009). Mesmo essa redução, contudo, foi revertida a partir de 2017 (Araújo \& Vieira, 2019).

Porém, uma menor efetividade das ações foi exercida sobre o monitoramento da exploração florestal ilegal na Amazônia, que, via de regra, acarreta degradação florestal (Asner et al., 2006), definida por Ghazoul et al. (2015) como um estado de sucessão interrompida e induzida antropogenicamente, onde os processos ecológicos subjacentes à dinâmica da floresta são diminuídos ou severamente restringidos, com a redução gradual e em longo prazo da cobertura do dossel, devido a incêndios florestais e à extração de madeira de forma não sustentável (Pinheiro et al., 2016). Embora os monitoramentos contínuos realizados na Amazônia também avaliem exploração, degradação florestal e estradas ilegais (IMAZON, 2020), são, em geral, voltados para a detecção do desmatamento anual (Shimabukuro et al., 2012), em tempo quase real (Diniz et al., 2015), bem como à qualificação das áreas já desmatadas (Almeida et al., 2016).

Uma das alternativas potenciais na mitigação de atividades antrópicas na Amazônia, em especial a exploração florestal ilegal, são os assentamentos de caráter ambientalmente diferenciado (Le Tourneau \& Bursztyn, 2010) que seguem os preceitos de desenvolvimento sustentável, o qual, de acordo com Gonçalves (2005), procura conciliar a necessidade de desenvolvimento econômico da sociedade com a promoção do desenvolvimento social e com o respeito ao meio ambiente. Entre estes, o Projeto de Desenvolvimento Sustentável (PDS), criado pela Portaria do Instituto Nacional da Colonização e Reforma Agrária (INCRA) n. 477/1999 (INCRA, 1999), modificada pela Portaria n. 1.040/2002 (INCRA, 2002a), é uma modalidade fundiária que integra a prática da agricultura, do extrativismo e de atividades florestais consideradas de baixo impacto ambiental (Bringel \& Gonçalves, 2014), balizadas pela manutenção de áreas de reserva legal (ARL) e áreas de preservação permanente (APP) (Brasil, 2012) e o estabelecimento de áreas de uso alternativo (AUA). Apenas nestas é permitida a substituição de vegetação nativa e formações sucessoras por outras coberturas do solo, desde que autorizada pelos órgãos ambientais. São exploradas em regime familiar, usualmente em lotes concedidos para uso de cada beneficiário do assentamento (Porro et al., 2018).

No estado do Pará, a opção por esse instrumento diferenciado deveu-se, sobretudo em sua fase inicial, ao trabalho realizado pela religiosa Dorothy Stang e à 
Comissão Pastoral da Terra, que idealizaram essa proposta que articula a reforma agrária à conservação ambiental na região da rodovia Transamazônica (Mendes \& Porro, 2015; Porro et al. , 2015, 2018). Contudo, antagonismos sociais, cuja expressão mais visível é simbolizada pelo assassinato de Dorothy Stang em 2005, provocaram desdobramentos que, mesmo passados 15 anos, ainda influenciam as perspectivas dos interessados na posse e no uso daquelas terras (Porro et al., 2018).

Em PDS, sobretudo considerando-se as limitações ambientais para supressão visando cultivo agrícola, tornase relevante a integração da atividade de manejo florestal como fonte de renda adicional e de oportunidades de trabalho para os assentados (Porro et al., 2020). O respeito à legislação ambiental torna-se necessário para que a retirada e a venda de madeira ocorram de forma legal, não causando empecilhos para o detentor e executor da atividade. Neste aspecto, de acordo com a legislação, um plano de manejo florestal deve ser protocolado ao órgão ambiental e revisado a cada cinco anos. A cada ano, uma autorização deve ser submetida para o manejo de uma unidade de produção anual (UPA), incluída em Plano Operativo Anual (POA), que deve ser licenciado por meio de uma Autorização para Exploração Florestal (AUTEF) (CONAMA, 2009).

Considerando-se as dimensões e características dos PDS, produtos e técnicas de sensoriamento remoto e geoprocessamento são capazes de identificar áreas de exploração florestal e a sua dinâmica em grandes extensões territoriais, úteis para áreas contínuas de difícil acesso (Souza Jr. et al., 2005; Lima et al., 2019; Shimabukuro et al., 2019) e de conflito agrário. Neste âmbito, o Instituto Nacional de Pesquisas Espaciais (INPE) mapeia anualmente, em caráter experimental e para fins de pesquisa, desde o ano de 2006, a região de tipologia florestal na Amazônia, por intermédio do projeto "Detecção de exploração madeireira em tempo quase real (DETEX)" (Guimarães \& Gomes, 2012).

Com a disponibilidade de imagens de satélite de forma contínua para a Amazônia, principalmente de sensores ópticos, as pesquisas desenvolvidas por Asner et al. (2005) e Grecchi et al. (2017) merecem destaque, ao elencarem diferentes métodos e métricas para a quantificação de tais áreas. São, ainda, relevantes os trabalhos que monitoram os efeitos posteriores à atividade de exploração florestal, tal como o de Shimabukuro et al. (2014), e o caráter de legalidade da atividade de acordo com o formato da infraestrutura de exploração, como o de Tritsch et al. (2016).

Decorridas duas décadas desde o surgimento da modalidade PDS, análises são necessárias quanto à sua efetividade na contenção da exploração florestal ilegal. Neste contexto, o presente estudo teve por objetivo investigar a dinâmica temporal da exploração florestal, utilizando produtos e técnicas de sensoriamento remoto e de geoprocessamento como instrumento de avaliação da efetividade desta atividade devidamente licenciada, constatada em vistorias realizadas em campo das áreas efetivamente licenciadas para a atividade por Autorizações de Exploração Florestal (AUTEF), emitidas pelo órgão ambiental.

\section{MATERIAIS E MÉTODOS}

\section{ÁREA DE ESTUDO}

A área de estudo selecionada para a presente análise foi o PDS Virola-Jatobá (PDS-VJ - coordenadas 3 12' 52.88" S e $51^{\circ} 18^{\prime} 38.89^{\prime \prime}$ O), implementado pelo Instituto Nacional de Colonização e Reforma Agrária no município de Anapu (INCRA, 2002b). Está localizado ao norte da rodovia BR-230 (Transamazônica), tendo sido criado pela Portaria SR01 n. 39/2002 (INCRA, 2002b). Compreendia, até agosto de 2018, dois módulos distintos, ocupando 39.602 hectares. A Portaria n. 1.470/2018 do INCRA determinou a anexação, em 31/08/2018, de duas glebas adicionais, o que permitiu a unificação de seu perímetro, de modo que a área total resultante passou a ser de 41.869 hectares (Figura 1), contendo 14 subglebas, com aproximadamente 3.000 hectares cada (INCRA, 2018). Nesta área, situam-se 160 parcelas de uso alternativo (AUA), concedidas a cada família assentada, sendo o restante da área considerada Reserva Legal (RL), de gestão e uso coletivo. 
É intensa a mobilidade de ocupantes nos lotes de uso alternativo. Em menos de 15 anos, desde a criação do assentamento, mais de 500 famílias passaram pelos
160 lotes. Apesar da área média dos lotes ser de 20,8 hectares, 22 lotes possuíam menos de 18 hectares, sendo que quatro deles apresentavam menos de 16 hectares e

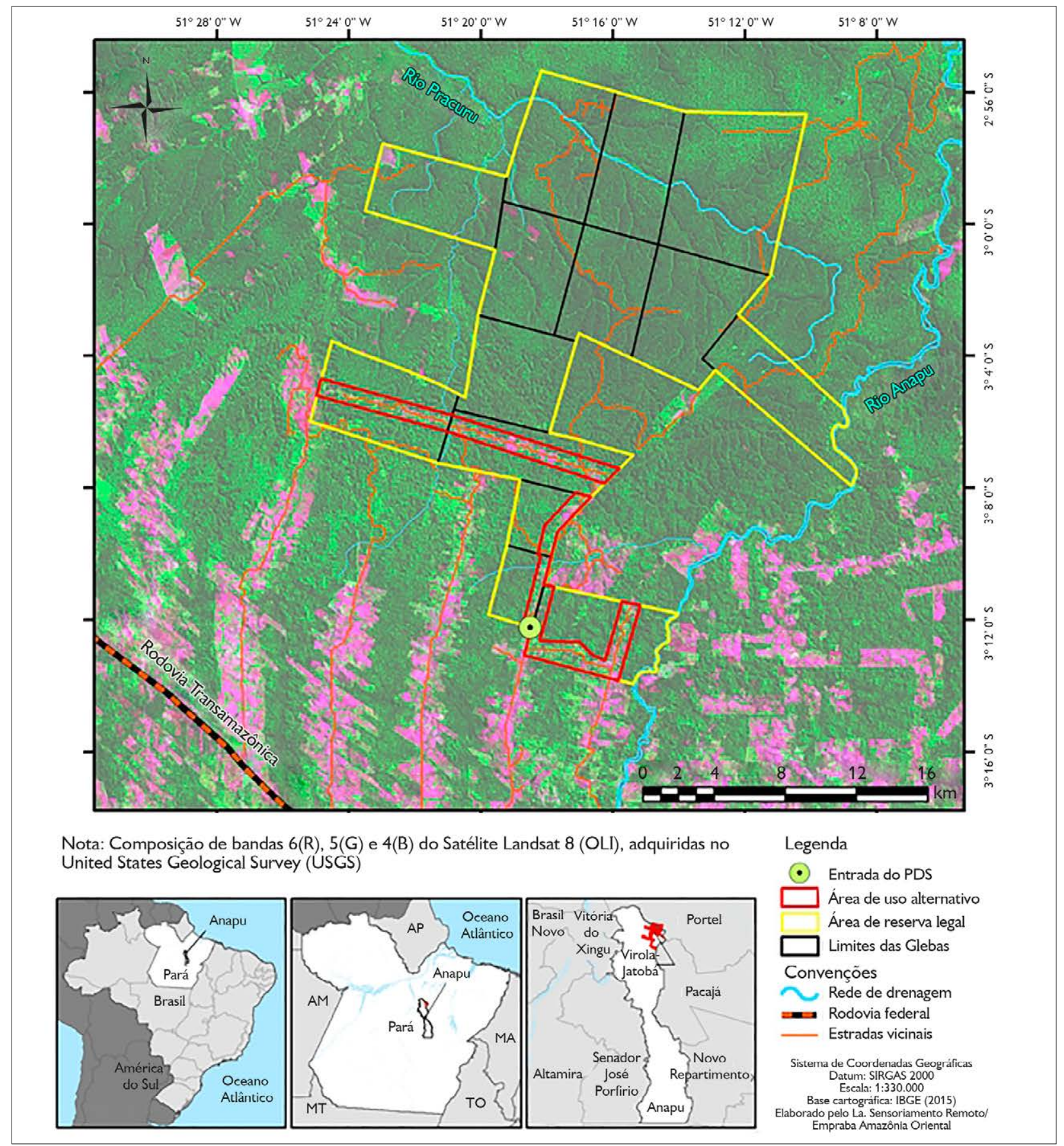

Figura 1. Mapa de localização do PDS Virola-Jatobá, município de Anapu, Pará.

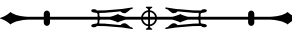


41 lotes, mais de 22 hectares, com cinco deles com mais de 30 hectares (Porro et al., 2018). Os lotes são destinados ao uso agropecuário por famílias assentadas. Contudo, pelo fato de a maior parte destas parcelas possuir cobertura florestal, o uso agrícola somente pode ocorrer mediante autorização de desmatamento concedida pelo órgão ambiental.

As características do ambiente biofísico do PDSVJ, notadamente a baixa fertilidade de seus solos, não privilegiam a agricultura voltada ao mercado, corroborando a vocação da área para a produção extrativa que resulte na comercialização de produtos florestais. As famílias do PDSVJ envolvidas em ação coletiva em torno desse enfoque são representadas pela Associação Virola Jatobá do PDS Anapu (AVJ) e pela Cooperativa de Produtores Agrícolas Orgânicos Florestais do PDS Virola-Jatobá (COOPAF).

A área do PDS Virola-Jatobá é drenada por igarapés tributários dos rios Anapu e Pracuru, sendo a malha viária existente subordinada à rodovia Transamazônica, que corre mais ao sul. Os solos ocorrentes apresentam boas propriedades físicas, profundidade, drenagem, porosidade e aeração, porém elevada acidez, baixa soma de bases e baixa saturação por bases trocáveis (Rodrigues et al., 2007). Tais limitações de natureza química para uso agropecuário são de fácil correção a partir de insumos, que, porém, são de custo inacessível à grande maioria dos produtores ali assentados.

O desmatamento no PDS-VJ era limitado a 6,7\% da área total em 2015 (Watrin et al., 2020), apresentando forte predominância de floresta, sendo esta situação observada mesmo na área de uso alternativo, que até aquele ano apresentava mais de 60\% de cobertura florestal (Porro et al., 2018). Nas áreas desmatadas predominam pastagens, mas também há presença de pequenas roças familiares com baixa diversificação da base produtiva, nas quais são importantes os cultivos anuais de mandioca e milho, apesar de excepcionalmente serem ainda observados pequenos pomares e cultivos de cacau. Em antigas áreas de uso agropecuário abandonadas, foi favorecido o surgimento de manchas de capoeiras (sucessão secundária) com estrutura e densidades variáveis. Em análise realizada para o ano de 2015,
10\% da AUA era coberta por capoeiras, percentual semelhante àquele sob cultivo agrícola, sendo 7\% para anuais e 3,5\% para perenes, ao passo que uma área superior a 20\% consistia de pastagens (Porro et al., 2018).

No PDS-VJ, o assentamento das famílias foi efetivamente formalizado a partir do ano de 2004. A primeira iniciativa de manejo florestal sustentável, com o objetivo de fomentar a extração madeireira e gerar renda aos assentados, ocorreu entre 2008 e 2012. Os assentados receberam treinamentos e qualificação em iniciativas de exploração florestal, no âmbito do Programa de Apoio ao Manejo Florestal Sustentável na Amazônia (ProManejo), gerido pelo Ministério do Meio Ambiente (MMA) e executado pelo Instituto Brasileiro de Meio Ambiente e dos Recursos Renováveis (IBAMA), com recursos financeiros de fontes nacionais e internacionais. Nesse período, a exploração ocorreu mediante à contratação de uma empresa que arcava com todos os custos operacionais e os riscos da atividade, pagando à AVJ por cada metro cúbico de madeira extraído (Mendes \& Porro, 2015; Porro et al., 2015, 2018). Irregularidades levaram à edição da Instrução Normativa INCRA n. 65/2010, que proíbe a exploração florestal nos assentamentos, por meio de parceria direta entre comunidade e empresas (INCRA, 2010). Assim, o plano de manejo no PDS-VJ foi interrompido entre 2013 e 2015. Uma segunda etapa de exploração florestal ocorreu em 2016-2017, com base em manejo comunitário gerido diretamente por organizações representativas dos assentados (COOPAF e AVJ) (Porro et al., 2020; artigo, em avaliação, intitulado "State-led agrarian and environmental policy failure in a Brazilian forest frontier: Anapu's Sustainable Development Project", de autoria de R. Porro e N. Porro). Para cada ano em que ocorreu a exploração florestal, foram fornecidas, pela Secretaria de Estado de Meio Ambiente e Sustentabilidade (SEMAS-PA), as AUTEF, com a especificação de área autorizada para exploração da UPA, bem como o respectivo volume autorizado para tal (Tabela 1). 
Tabela 1. Detalhamento das autorizações para exploração florestal (AUTEF), fornecidas pelo órgão responsável pelo licenciamento no PDS para o período analisado. A UPA1, com 180 ha inventariados em 2007 em caráter experimental, não foi explorada. Legenda: * = caso solicitado pelo detentor da AUTEF, seu prazo de validade, ou seja, o direito à exploração florestal (corte, derruba, arraste de toras de árvores) pôde ser estendido por um ano a contar da data de validade, o que ocorreu no caso das UPA 5 e 6. Fonte: elaborada a partir dos dados das Autorizações de Exploração Florestal emitidas pela SEMAS-PA.

\begin{tabular}{|c|c|c|c|c|c|}
\hline & \multicolumn{2}{|c|}{ Área autorizada (ha) } & \multirow{2}{*}{$\begin{array}{l}\text { Volume autorizado para } \\
\text { exploração }\left(\mathrm{m}^{3} / \mathrm{ha}\right)\end{array}$} & \multirow{2}{*}{$\begin{array}{c}\text { Data da Autorização } \\
\text { para Exploração Florestal } \\
\text { (AUTEF) }\end{array}$} & \multirow{2}{*}{$\begin{array}{c}\text { Data de validade da } \\
\text { AUTEF* }\end{array}$} \\
\hline & Total & Líquida & & & \\
\hline UPA 2 & 501,06 & 415,05 & 29,12 & 05/06/2008 & 01/04/2009 \\
\hline UPA 3 & 504,72 & 462,06 & 26,86 & $31 / 08 / 2009$ & $31 / 08 / 2010$ \\
\hline UPA 4 & 972,72 & 952,72 & 29,99 & $05 / 10 / 2010$ & $05 / 10 / 2011$ \\
\hline UPA 5 & $1.089,93$ & $1.058,29$ & 28,30 & $12 / 06 / 2011$ & $12 / 06 / 2013$ \\
\hline UPA 6 & 545,27 & 440,87 & 26,40 & $23 / 11 / 2015$ & $23 / 11 / 2017$ \\
\hline
\end{tabular}

\section{PROCESSAMENTO DOS DADOS ESPACIAIS}

Foram utilizadas imagens da série Landsat, dos sistemas sensores Thematic Mapper - TM (Landsat 5), Enhanced Thematic Mapper Plus - ETM+ (Landsat 7) e Operational Land Image (Landsat 8), considerando as bandas do vermelho, infravermelho próximo e infravermelho médio, ortorretificadas e com correção atmosférica. Para a correção atmosférica, as imagens foram convertidas de número digital (ND) para radiância no topo da atmosfera pelo método Top of the Atmosphere (TOA), utilizando os parâmetros de radiância espectral do satélite da série Landsat e, assim, posteriormente convertidas para reflectância na superfície terrestre (Chander et al., 2007), disponibilizadas no catálogo do Serviço Geológico Americano (USGS, s. d.) (University of Maryland, 2000; Gutman et al., 2013).

Como critério de seleção das imagens de estudo, levou-se em consideração aquelas com menor cobertura de nuvens possível ou que tivessem pelo menos uma gleba livre de nuvens para serem utilizadas. Com base neste critério de seleção, para o período de análise de 1984 a 2014, foram utilizadas as imagens definidas na Tabela 2.

Após a aquisição das imagens, o banco de dados foi organizado em linguagem PostgresSQL, no software de geoprocessamento TerraAmazon, versão 4.6.3, considerado um sistema de informação geográfica (SIG)
Tabela 2. Imagens da série Landsat utilizadas na área do PDS VirolaJatobá, referentes a órbita/ponto - 225/062. Fonte: elaborada de acordo com os critérios de seleção estabelecidos para a análise da área de estudo.

\begin{tabular}{|c|c|}
\hline Sistema sensor & Data de imageamento \\
\hline L8-OLI & $2 / 08 / 2016$ \\
\hline L8-OLI & $16 / 08 / 2015$ \\
\hline L8-OLI & $3 / 12 / 2014$ \\
\hline L8-OLI & $21 / 10 / 2013$ \\
\hline L7-ETM+ & $2 / 10 / 2012$ \\
\hline L5-TM & $4 / 7 / 2011$ \\
\hline L5-TM & $27 / 9 / 2010$ \\
\hline L5-TM & $19 / 11 / 2009$ \\
\hline L5-TM & $11 / 7 / 2008$ \\
\hline L5-TM & $23 / 6 / 2007$ \\
\hline L5-TM & $4 / 6 / 2006$ \\
\hline L7 - ETM+ & $13 / 9 / 2005$ \\
\hline L5-TM & $1 / 8 / 2004$ \\
\hline L7-ETM+ & $23 / 8 / 2003$ \\
\hline L5-TM & $25 / 10 / 2000$ \\
\hline L7-ETM+ & $17 / 6 / 2002$ \\
\hline L5-TM & 4/08/1999 \\
\hline L5-TM & $21 / 7 / 1994$ \\
\hline L5-TM & 23/6/1984 \\
\hline
\end{tabular}

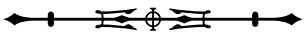


destinado a apoiar projetos de cunho ambiental. Os planos de informação foram projetados com sistema de coordenadas Universal Transversa de Mercator (UTM), zona 22 Sul e Datum planimétrico geocêntrico Sirgas 2000 (Sistema de Referência Geocêntrico para as Américas).

Assim, foram efetuadas as operações de processamento digital de imagens, baseando-se na metodologia do DETEX, com imagens de satélites de média resolução espacial, idealizado pelo INPE (Guimarães \& Gomes, 2012; Figura 2). Para isso, foi aplicado o Modelo Linear de Mistura Espectral (MLME), no intuito de separar três componentes principais: solo, sombra e vegetação, proporcionalmente contidos em cada pixel, provenientes da integração da radiância dos elementos captados pelo sensor em cada elemento de resolução (Shimabukuro \& Smith, 1991).

Posteriormente, foi realizada a operação aritmética da razão entre os componentes solo e vegetação extraídos do modelo de mistura, acrescida de ganho e offset, com valores de 90 e 50 respectivamente (Figura 2), em que é aplicada na equação 1 :

$$
\mathrm{FC}=\text { Ganho* }\left(\frac{\mathrm{R} 0}{\mathrm{R} 1}\right)+\text { Offset }
$$

Onde: $\mathrm{FC}=$ fator de calibração; ganho = valores de diferentes respostas dos detectores expostos ao mesmo nível de iluminação; R0 = imagem fração solo; R1 = imagem fração vegetação; offset $=$ resposta diferente de zero quando não há nível de iluminação, sendo diferente para cada detector.

De acordo com Fonseca et al. (2004), o objetivo da calibração relativa é balancear a resposta dos detectores de cada banda quando o instrumento sensor (CBERS-2, por exemplo) observa uma superfície uniforme, ou seja, para uma mesma banda, todos os detectores têm que gerar o mesmo sinal quando são sensibilizados por uma mesma fonte.

Em sequência, um contraste foi aplicado no produto gerado, considerando a metade final da função de distribuição de frequência dos dados, para realçar as áreas de exploração. Assim, após esta etapa, o método de fatiamento foi empregado, sendo que, para Oliveira et al. (2017, p. 2219), consiste em dividir o histograma da imagem em faixas de níveis de cinza, sendo atribuídas de forma que apresentem o mesmo intervalo de níveis de cinza, ou que contenham o mesmo número de pixels, ou, ainda, apresentem intervalos variáveis.

Por último, com o auxílio do produto gerado pelo método de fatiamento e com a imagem de fração composta, foi possível interpretar as imagens, classificando-as por meio da vetorização das áreas de exploração florestal. Assim, foi possível quantificar as áreas exploradas no PDS-VJ e suas Unidades de Produção Anual (UPA), contendo o conjunto de feições da infraestrutura para tal, consistindo em estradas principais, secundárias, ramais de exploração, pátios de estocagem e de evidências de queda das árvores abatidas.

Desta forma, a quantificação das áreas de exploração florestal foi realizada conforme metodologia proposta por Guimarães \& Gomes (2012), as quais foram comparadas com a área das respectivas AUTEF, sendo que as verificações em campo do que foi detectado via sensoriamento remoto e do que foi efetivamente autorizado e explorado foram realizadas no período de setembro a novembro de 2014 , para as UPA 2 a 5, e em setembro de 2017, para a UPA 6. Os resultados das análises empreendidas neste estudo são, portanto, efetuados de acordo com três contextos distintos: as áreas de cada uma das AUTEF do plano de manejo, já que tais autorizações possuem área total autorizada para a realização de atividades de manejo; a superfície total do PDS-V) (41.869 hectares, que incluem reserva legal e área de uso alternativo), já que se supõe o caráter da ilegalidade em áreas de preservação permanente, vedadas para o manejo florestal pelo código florestal brasileiro (Brasil, 2012); e um polígono mais amplo, no qual está situado o PDS-V], totalizando 147.588,60 hectares. A inclusão deste terceiro contexto se justifica pelo fato de as áreas limítrofes ao PDS, em sua maior parte, serem compostas por terras não destinadas (devolutas), sob domínio da união, contendo florestas públicas nas quais sistematicamente ocorre exploração florestal ilegal.

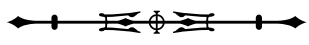




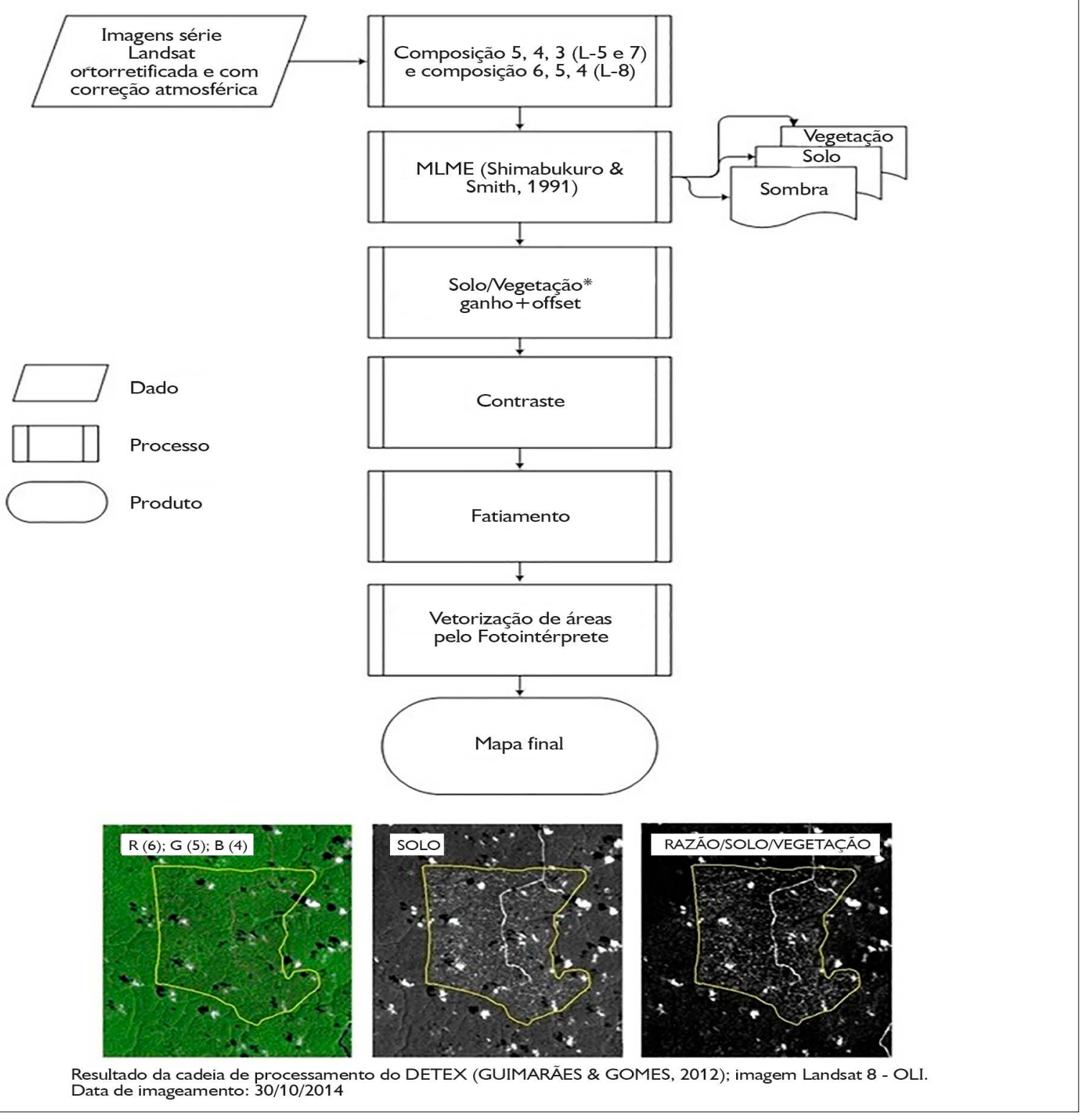

Figura 2. Metodologia desenvolvida para o programa de monitoramento de exploração florestal na Amazônia (projeto DETEX) (Guimarães \& Gomes, 2012).

\section{RESULTADOS}

\section{DINÂMICA TEMPORAL E ESPACIAL DA EXPLORAÇÃO FLORESTAL}

A análise multitemporal realizada identificou total de 31.240,80 hectares de alterações causadas por exploração florestal ao longo do período de 18 anos (1999-2016). Cerca de dois terços $(65,4 \%)$ destas alterações, ou 20.429,07 hectares, ocorreram no perímetro do PDS-VJ, sendo que a área explorada no interior das UPA, evidenciada nas imagens, totalizou 2.330,79 hectares, ou 13,4\% das alterações (Figura3). Aanálise identificou que 1.909,73 hectares explorados

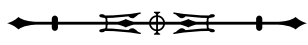


nas UPA correspondem a áreas devidamente licenciadas; consequentemente, as explorações florestais irregulares, identificadas pelo método no PDS-VJ, alcançaram 18.519,34 hectares, ou $90,7 \%$ do total das alterações ali observadas.

\section{Período anterior ao assentamento}

A análise demonstrou que nos anos de 1984 e 1994 ainda não haviam sido evidenciadas nas imagens alterações na cobertura florestal passíveis de serem detectadas. Todavia, para os anos de 1999, 2000 e 2002, ainda anteriores à criação do projeto de assentamento, e para 2003 e 2004, anos que antecederam à instalação das famílias no mesmo local, foram identificadas áreas de exploração no interior do PDS-VJ. O total da área explorada até 2004, anterior ao assentamento das famílias, alcançou 27.294,84 hectares, correspondendo a $87,4 \%$ das alterações totais. Desse montante, 17.042,49 hectares ocorreram no interior da área que posteriormente viria a se tornar assentamento, correspondendo a 83,4\% das alterações na área do PDS-V] e 92,0\% das explorações irregulares ali realizadas, sendo 318,64 hectares no interior das atuais UPA (Figura 4).

\section{Período posterior ao assentamento, sem vigência de licenciamento florestal}

Entre o assentamento das famílias, em 2004, e o início da vigência do plano de manejo florestal sustentável conduzido pela AVJ, em 2008, foram identificadas explorações em 471,39 hectares no PDS-VJ, de um total de 478,80 hectares identificados nestes anos, correspondendo a 2,3\% das alterações totais observadas no assentamento. Além disso, entre 2013 a 2015 não houve licenciamento florestal devido à Instrução Normativa n . 65/2010 do INCRA (INCRA, 2010), que impediu a continuidade de exploração florestal nos assentamentos quando realizada de forma direta por meio de empresas. Mesmo assim, o método identificou alteração em 443,29 hectares na área do PDS-VJ de um total de 974,68 hectares para o polígono completo, correspondendo a 2,2\% do total da exploração observada no assentamento ao longo do período. Assim, a soma das alterações verificadas após a criação do PDS-VJ, nos anos sem vigência de licenciamento florestal, alcança 914,68 hectares, perfazendo 4,5\% das alterações na área do PDS-V] e 4,9\% das explorações irregulares ali realizadas.

Portanto, entre 1999 e 2007, período anterior ao início das atividades de manejo florestal executadas pelos assentados, e entre 2013-2015, período em que o Plano de Manejo estava oficialmente suspenso, foram identificadas, na área do PDS-V], explorações em 17.957,17 hectares, correspondendo a 87,9\% das alterações ocorridas durante todo o período analisado, e em sua totalidade realizadas de forma ilegal, representando 96,9\% do total de explorações irregulares efetuadas no assentamento. Da área total explorada nesses períodos, cerca de 319 hectares (pouco mais de 1\%) sobrepõem-se às UPA do plano de manejo florestal posteriormente licenciadas.

\section{Período com vigência de licenciamento florestal}

Entre 2008-2012 e em 2016, quando vigoravam as AUTEF concedidas pelo órgão licenciador, o método identificou explorações florestais em 2.471,90 hectares na área do PDS-VJ, sendo 1.909,73 hectares nas UPA dos respectivos anos, estas últimas, portanto, explorações devidamente licenciadas. Nesse período, destaca-se que, em áreas do polígono analisado fora do PDS-V], foram detectadas alterações em apenas 20,6 hectares. Durante a vigência do licenciamento florestal, a área das alterações identificadas pelo método correspondeu a 12,1\% do total de alterações no PDS-VJ e $8 \%$ quando considerado o polígono completo.

Ao longo do período de vigência de AUTEF, identificaram-se alterações que podem ser consideradas explorações irregulares perfazendo um total de 562,17 hectares, equivalente a 2,8\% do total de alterações na área do PDS-VJ e a cerca de 3,1\% do total da exploração ilegal ali identificada nos 18 anos compreendidos pela análise. Deste total, 459,77 hectares foram verificados em outras áreas do PDS-V] que não sejam as UPA, e 102,42 hectares foram explorados nas UPA, porém em anos diferentes dos que constavam em AUTEF então vigentes. 


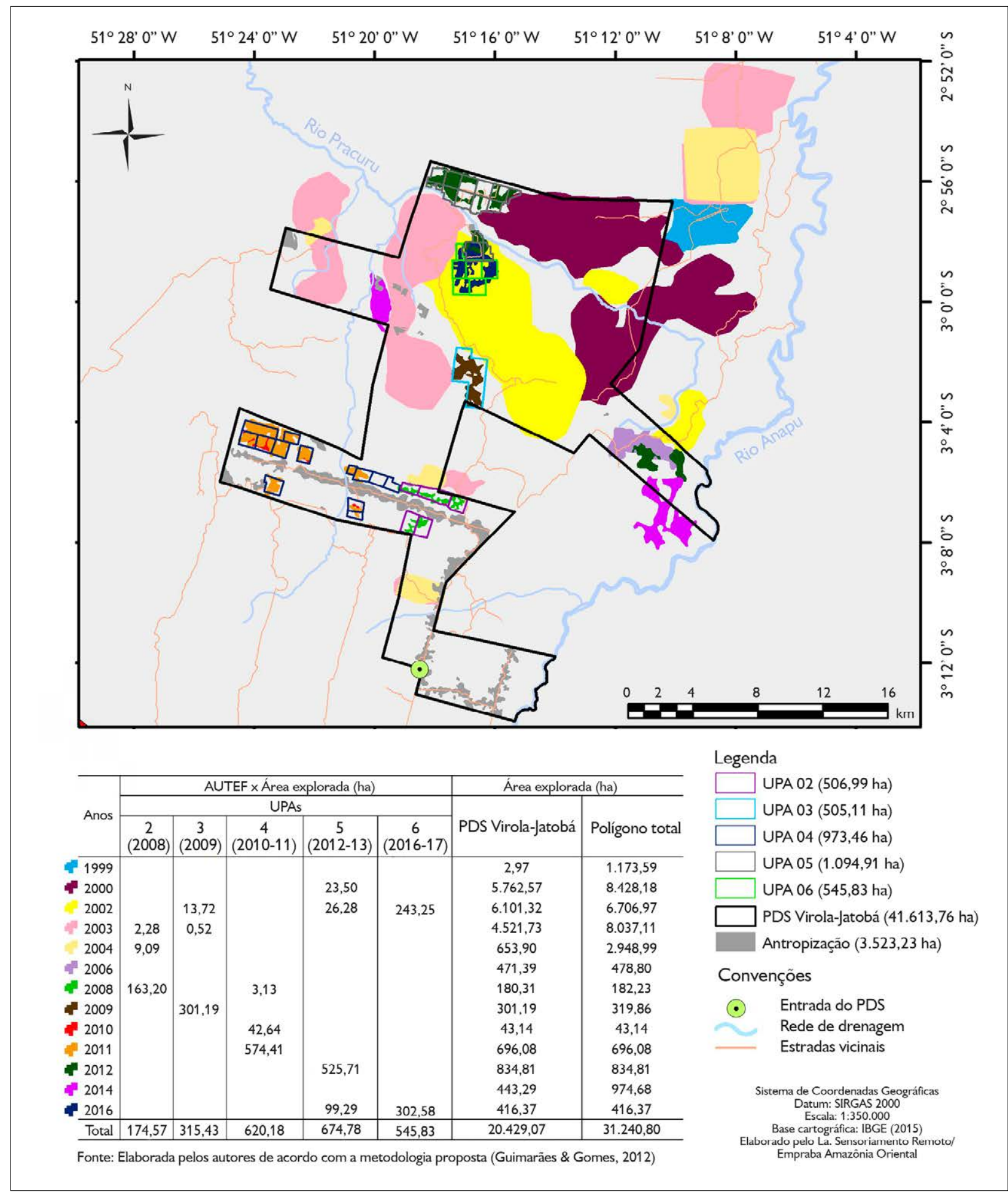

Figura 3. Dinâmica das áreas de exploração florestal no PDS Virola-Jatobá, município de Anapu, Pará, no período de 1999-2016. Entre parênteses, na tabela, são apresentados os respectivos anos de exploração das AUTEF.

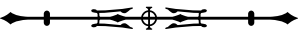




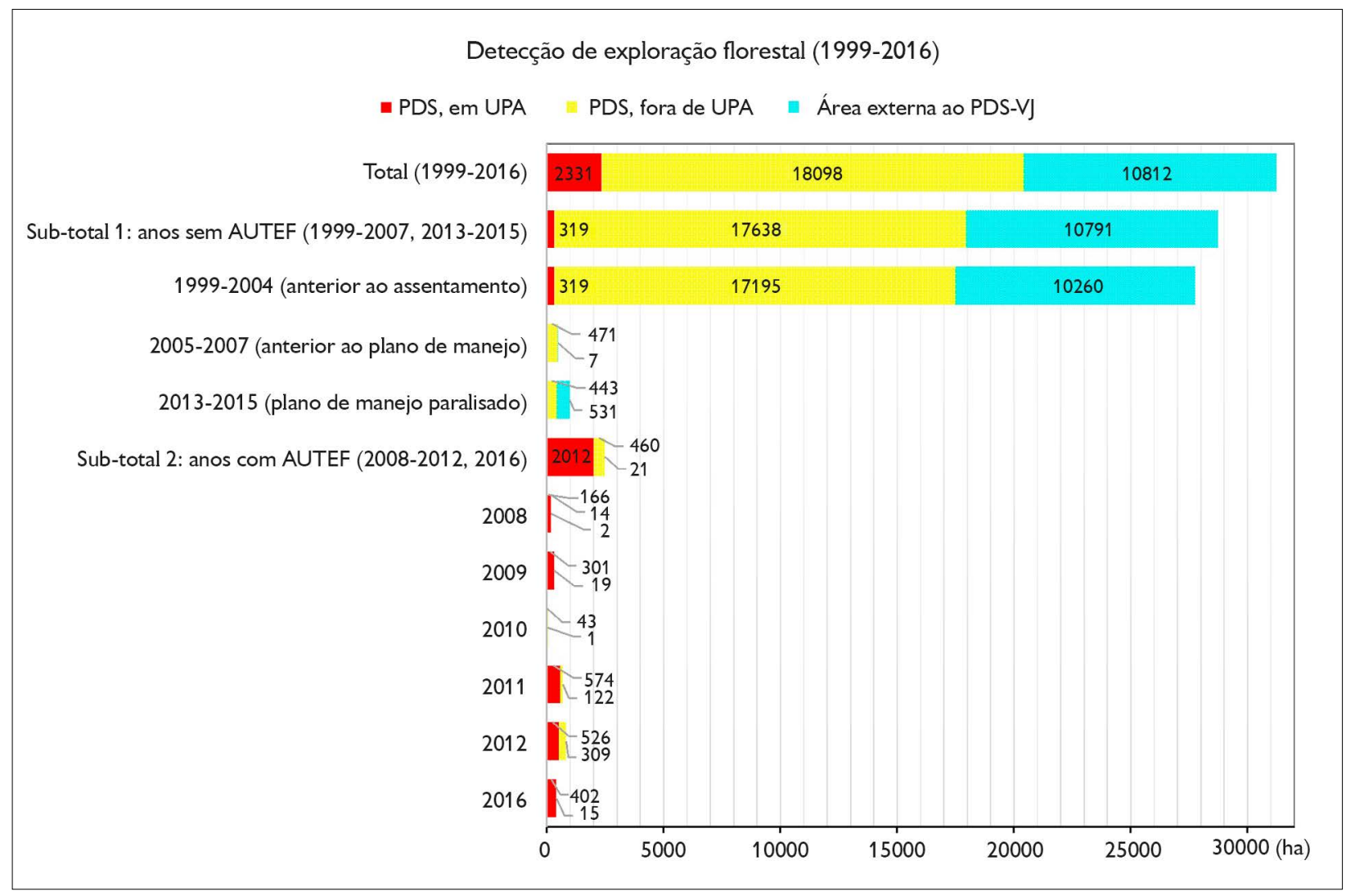

Figura 4. Detecção de exploracão florestal na área estudada, no período de 1999-2016.

\section{DIFERENÇA ENTRE DETECÇÃO PELO MÉTODO E ÁREA LICENCIADA}

Nos anos de 2008 e 2009, embora tenham sido emitidas as primeiras AUTEF, para exploração de 501 e 505 hectares (respectivamente UPA 2 e 3), o método identificou alterações de 163 e 301 hectares, correspondendo a 33\% e 60\% das áreas totais licenciadas' (Tabela 3). Já para o total de 973 hectares autorizados em 2010 na UPA 4, foram detectados 42,64 hectares naquele ano e 574,41 hectares no ano seguinte, totalizando 617,05 hectares na referida UPA, correspondendo à identificação de efetiva exploração florestal em $64 \%$ da área total de manejo nela autorizada e executada.
Tabela 3. Áreas licenciadas no âmbito do Plano de Manejo, detecção de exploração florestal pelo método e percentual de detecção. Legenda: * ${ }^{*}$ a exploração se estendeu até o ano seguinte.

\begin{tabular}{c|c|c|c|c}
\hline & \multicolumn{2}{|c|}{ Área licenciada (ha) } & \multicolumn{2}{c}{$\begin{array}{c}\text { Detecção pelo } \\
\text { método }\end{array}$} \\
\hline Ano AUTEF & Total & Líquida & ha & $\%$ \\
\hline 2008 & 501,06 & 415,05 & 163,20 & $32,6 \%$ \\
\hline 2009 & 504,72 & 462,06 & 301,19 & $59,7 \%$ \\
\hline 2010 & $972,72 *$ & $952,54 *$ & 42,64 & $63,4 \%$ \\
\hline 2011 & - & - & 574,41 & - \\
\hline 2012 & $1.089,93$ & $1.058,29$ & 525,71 & $48,2 \%$ \\
\hline 2016 & 545,27 & 440,87 & 302,58 & $55,5 \%$ \\
\hline Total & $3.613,7$ & $3.328,81$ & $1.909,72$ & $52,8 \%$ \\
\hline & & & &
\end{tabular}

Utilizou-se a área total licenciada, e não a área líquida, para os cálculos de sobreposição para viabilizar a comparabilidade com o método de detecção, aplicado para a área total da UPA, ou seja, sem excluir as áreas de APP ou outras não inseridas quando do licenciamento.

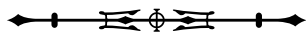


Em 2012, a autorização para a UPA 5 correspondia a 1.090 hectares. Do total de 834,81 hectares efetivamente detectados pelo método, integralmente no interior do PDS, 525,71 hectares situam-se na área licenciada pela AUTEF (UPA 5), correspondendo a 48\% da mesma. Em 2016, quando o plano de manejo florestal foi reativado com gestão da própria comunidade (AVJ, 2015), foram identificadas alterações devidamente autorizadas em 401,87 hectares, ou 74\% da área licenciada de 545 hectares, notando-se, porém, que cerca de um terço desta alteração foi evidenciada na contígua UPA 5. Destaca-se que a efetiva exploração das áreas totais licenciadas para as UPA foi à época constatada em campo, sendo que, no caso da UPA 4, a exploração foi, de fato, concluída no ano seguinte.

Considerando-se o licenciamento por todas as AUTEF expedidas, com área total de 3.613,7 hectares, o método identificou alterações correspondentes a 52,8\% desta área.

\section{DISCUSSÃO}

As análises realizadas no PDS-VJ permitiram identificar que alterações não autorizadas na floresta, ou seja, explorações florestais não correspondentes às áreas licenciadas por AUTEF, totalizaram 18.519,34 hectares. Cabe destacar que 92\% desta alteração ocorreram antes do assentamento das famílias, e outros $4,9 \%$ se deram durante períodos nos quais não havia sido ainda iniciado ou estava interrompido o plano de manejo florestal conduzido pela associação local.

Abordando a detecção de exploração florestal ilegal, em situações similares ao evidenciado na presente análise, Matricardi et al. (2013) elucidam que, em localidades fora das redes de áreas protegidas, a efetividade da proteção é menor, e mesmo as florestas contidas em áreas protegidas podem sofrer com os impactos de exploração ilegal. Além disso, o estudo de Barreto et al. (2006) reforça os resultados obtidos, já que estimou que mais de $40 \%$ da extração seletiva na Amazônia brasileira foi considerada como ilegal e, consequentemente, não regulamentada, no período de 2001 a 2004, sobretudo em áreas florestais não contempladas por unidades de conservação.
Dois aspectos relacionados à identificação de exploração ilegal na área licenciada merecem destaque. Inicialmente, observa-se que uma parcela substancial do total identificado como explorado irregularmente durante o período de licenciamento corresponde a áreas limítrofes às respectivas UPA. Técnicos e manejadores que participaram da exploração conduzida pela AVJ relataram que a classificação dessas áreas como de exploração irregular se deve a inconsistências entre a localização exata dos polígonos mapeados e a realidade de campo, resultado de divergências entre bases cartográficas utilizadas (comunicação pessoal). Neste caso, a análise identificou uma área de 273,67 hectares, correspondendo a $8,2 \%$ do total das UPA e a $47 \%$ das alterações ao longo dos anos em que foram emitidas AUTEF.

Esse fato foi observado em três situações distintas. A primeira se refere a limites entre unidades de preservação ambiental contíguas, como entre as UPA 2 e 4 e as UPA 5 e 6, totalizando 102,42 hectares. A segunda situação envolve limites entre as UPA e outras áreas do PDS-VJ, como ocorreu principalmente na UPA 4, com alterações totalizando 150,67 hectares. A terceira situação ocorreu em 20,58 hectares, quando unidades estão próximas ao limite entre o PDS-VJ e áreas contíguas. Pressões por recursos florestais em áreas limítrofes também foram constatadas nos estudos de Pinheiro et al. (2016), Celentano et al. (2017, 2018) e Souza et al. (2017), os quais analisaram a efetividade de áreas protegidas e/ou de uso múltiplo e também apontaram alterações expressivas em sua cobertura florestal.

$O$ segundo aspecto refere-se às implicações para licenciamento resultantes da identificação de áreas exploradas no passado, sem autorização do órgão ambiental competente, como verificado no ano de 2002, em áreas que posteriormente são objeto de AUTEF, como ocorrido nas UPA 5 e 6, totalizando, respectivamente, 26,28 e 243,25 hectares. Conforme disposto na Portaria n. 63/2014 da SEMAS-PA (SEMAS-PA, 2014), tais áreas devem ser submetidas à análise temporal de imagens de satélite processadas pelo setor de geotecnologia da secretaria, sendo, então, utilizado o Índice Normalizado de 
Diferença de Fração (NDFI), desenvolvido por Souza Jr. et al. (2005) como um processo para separar alterações do dossel devido à exploração e a incêndios florestais daquelas causadas por outros distúrbios naturais em floresta tropical. Contudo, limitações na identificação destas áreas com uso de imagens com resolução espacial similar à da série Landsat (30 m) ocorrem em razão da mistura complexa de vegetação morta e viva, sombreamento e solos encontrados em todos os ambientes de floresta. Tais limitações podem ser contornadas, de acordo com Asner et al. (2009), pela identificação com mais precisão na escala de subpixel, usando-se a técnica chamada de análise de mistura spectral (Shimabukuro \& Smith, 1991), também adotada na metodologia do DETEX (Guimarães \& Gomes, 2012), empregada no presente estudo.

De acordo com as normas do licenciamento, a autorização para exploração florestal somente será concedida caso a exploração anterior tenha ocorrido há mais de 12 anos e tenha resultado em estado de degradação considerado baixo ou intermediário (SEMAS-PA, 2015a). A autorização concedida deverá levar em consideração a capacidade de recuperação da floresta, o que determina adequação da volumetria máxima aprovada, via de regra, em função do número de anos decorridos desde a primeira exploração.

Conforme detectado pelo presente estudo, a situação descrita ocorreu em duas ocasiões. Em 2012, quando do licenciamento da UPA 5, ainda não havia sido publicada a Portaria $n^{\circ}$. 63/2014 da SEMAS-PA (SEMASPA, 2014), não sendo, assim, definidos descontos na volumetria autorizada. Caso a análise fosse realizada e seus resultados fossem semelhantes ao identificado neste estudo, os 26,28 hectares alterados em 2002 deveriam ser excluídos da área autorizada. Já em 2015, no licenciamento da UPA 6, o órgão ambiental detectou exploração anterior, porém no montante de 50,76 hectares (SEMAS-PA, 2015b), contrastando com área muito superior detectada pela metodologia DETEX. Devido à indisponibilidade de software para analisar as imagens adequadamente, o órgão ambiental optou por excluir os 50,76 hectares da AUTEF, não sendo utilizado o critério de adequação de volumetria.

Analisando os resultados obtidos, o período de 1999 a 2004, que precedeu o estabelecimento do PDSVJ e o início do plano de manejo florestal pelas famílias assentadas, é caracterizado pela ocorrência massiva de explorações ilegais, reproduzindo situações em que florestas degradadas dominam a paisagem em regiões de ocupação consolidada na Amazônia brasileira, causando massiva perda de diversidade, aumento da emissão de $\mathrm{CO}_{2}$ e potencializando problemas sociais (Blanc et al., 2017).

A partir de 2008, com o início do manejo florestal comunitário pela AVJ, observa-se redução significativa na incidência de explorações florestais ilegais na área licenciada, embora o plano de uso do PDS-VJ tenha sido debatido, negociado e aprovado somente em 2016, o que contribuiu para outras irregularidades ambientais ali ocorridas (Porro et al., 2018, 2020). Dessa forma, o manejo florestal sustentável é componente essencial para a viabilidade desta modalidade fundiária e, para que seja efetivo, são necessários procedimentos adequados para seu criterioso licenciamento, levando-se em consideração aspectos inerentes à capacidade organizacional e financeira dos beneficiários. De acordo com Silva et al. (2009), o manejo deve ser conduzido de forma que as florestas forneçam continuamente os benefícios econômicos, ecológicos e sociais decorrentes de um aproveitamento florestal adequado.

Os desafios para o manejo florestal comunitário abrangem, contudo, inúmeras dimensões. No que tange aos impactos ambientais, é imprescindível contínuo treinamento e observância de técnicas adequadas para que o impacto seja realmente reduzido, observando o plano de exploração, planejamento de estradas, planejamento e construção de pátios de estocagem e controle do sistema - planejamento, execução e avaliação (Braz et al., 1998) -, sendo que tais premissas foram seguidas pela $\mathrm{AVJ}$ com a retomada do projeto ocorrida em 2016.

O contexto econômico é também temerário, pois, de acordo com Humphries et al. (2012), mesmo havendo 
uma taxa de retorno positiva em um ciclo de exploração, tanto em manejo comunitário como em empreendimentos privados em larga escala, é duvidoso que futuras colheitas produzam níveis de retorno semelhantes, devido às taxas de crescimento mais lentas do que o previsto e/ou à incursão da exploração ilegal de madeira, o que, de fato, foi constatado no presente estudo, ao longo dos anos de análise, com a ocorrência de exploração madeireira não autorizada em florestas públicas do entorno, em áreas maiores do que as autorizadas via AUTEF no PDS-VJ.

Além disso, dinâmicas irregulares de exploração também foram corroboradas pelos estudos de Greenpeace (2014) e Brancalion et al. (2018), que identificaram fraudes como a solicitação de extração de densidades de espécies muito acima do estabelecido em literatura, caracterizando indícios de que os créditos gerados por esta área de manejo foram usados para 'lavar' a madeira ilegal, oriunda de outros lugares.

Em contextos de ilegalidade, Muttaqin et al. (2019) identificaram que as comunidades que manejam e conservam florestas de forma comunitária influenciam e são afetadas pela degradação florestal, reforçando a necessidade de planos robustos para o manejo sustentável dos ecossistemas florestais, bem como a importância da participação das comunidades para a redução da ilegalidade, já preconizados no PDS-VJ, por ocasião da criação da modalidade (INCRA, 2002b).

\section{CONSIDERAÇÕES FINAIS}

Os resultados apresentados ratificam as pressões existentes na área de estudo, que favorecem a ilegalidade da exploração florestal. Ao longo dos anos em que ocorreu a exploração florestal licenciada por AUTEF, o método adotado deixou de identificar alterações em 1.703,98 ha dos 3.613,70 ha executados, ou seja, 47,2\% da área efetivamente licenciada, cuja exploração foi constatada em campo ao longo do período de análise. Com efeito, o índice de 53\% de detecção resulta satisfatório, dadas as condições locais e a resolução espacial das imagens utilizadas, passíveis de melhoras, caso fossem adotadas imagens de sensores de resolução espacial mais fina e, em alguns casos, devido à alta cobertura de nuvens nos períodos em que ocorre a exploração florestal.

O montante de $96,9 \%$ da exploração florestal não autorizada observada na área do PDS-VJ ocorreu durante períodos em que não vigorava o plano de manejo florestal comunitário devidamente apoiado pelos órgãos públicos, ou seja, apesar de até o momento inúmeras dificuldades de gestão para execução da política de assentamentos atestarem que a modalidade PDS não tenha se mostrado eficaz como estratégia para consolidação de meios de vida sustentáveis para os assentados no PDS-V) (Porro et al., 2020; artigo, em avaliação, intitulado "State-led agrarian and environmental policy failure in a Brazilian forest frontier: Anapu's Sustainable Development Project", de autoria de R. Porro e N. Porro), o manejo florestal se apresenta como alternativa promissora na contenção de explorações não autorizadas, uma vez que apenas 3,1\% destas alterações ocorreram durante a vigência do plano de manejo florestal comunitário, ao longo de seis dos 18 anos compreendidos por esta análise.

Políticas públicas de regularização fundiária na Amazônia e de regulamentação das atividades econômicas e melhoria da infraestrutura básica nos PDS são, portanto, fundamentais para o estabelecimento de uma melhor conjuntura econômico-social e, consequentemente, para a sustentabilidade destes locais, tendo o Estado como seu principal indutor, fundamental na contenção da extração ilegal de madeira. Todavia, contingenciamentos de recursos do orçamento federal e a consequente redução de atividades de fiscalização e treinamento de funcionários, bem como recentes proposições, pelo Governo Federal, de redução de áreas protegidas e relaxamento no status de seu grau de proteção são indicativos concretos da baixa priorização de causas socioambientais, limitando a eficácia destas ações.

\section{AGRADECIMENTOS}

Os autores agradecem à Empresa Brasileira de Pesquisa Agropecuária (EMBRAPA), à Fundação Amazônia de Amparo a Estudos e Pesquisas e ao Conselho de 
Pesquisas Sueco, pelo apoio financeiro para a execução deste estudo. Tais agradecimentos são extensivos aos produtores rurais do PDS Virola-Jatobá, por terem permitido a convivência e acompanhado as equipes de pesquisa durante as atividades de campo.

\section{REFERÊNCIAS}

ABERS, R. N., M. S. OLIVEIRA \& A. K. PEREIRA, 2017. Inclusive development and the asymmetric state: big projects and local communities in the Brazilian Amazon. The Journal of Development Studies 53(6): 857-872. DOI: http://dx.doi.org/1 $0.1080 / 00220388.2016 .1208177$

ALMEIDA, C. A. D., A. C. COUTINHO, J. C. D. M. ESQUERDO, M. ADAMI, A. VENTURIERI, C. G. DINIZ, N. DESSAY, L. DURIEUX \& A. R. GOMES, 2016. High spatial resolution land use and land cover mapping of the Brazilian Legal Amazon in 2008 using Landsat-5/TM and MODIS data. Acta Amazonica 46(3): 291-302. DOI: https://doi.org/10.1590/1809-4392201505504

ARAÚJO, R. \& I. C. G. VIEIRA, 2019. Desmatamento e as ideologias da expansão da fronteira agrícola: o caso das críticas ao sistema de monitoramento da floresta amazônica. Sustentabilidade em Debate 10(3): 366-378. DOI: https://doi.org/10.18472/ SustDeb.v10n3.2019.27258

ARIMA, E. Y., P. BARRETO, E. ARAÚJO \& B. SOARES-FILHO, 2014. Public policies can reduce tropical deforestation: lessons and challenges from Brazil. Land Use Policy 41: 465-473. DOI: https://doi.org/10.1016/j.landusepol.2014.06.026

ASNER, G. P., D. E. KNAPP, E. N. BROADBENT, P. J. OLIVEIRA, M. KELLER \& J. N. SILVA, 2005. Selective logging in the Brazilian Amazon. Science 310(5747): 480-482. DOI: https://doi. org/10.1126/science. 1118051

ASNER, G. P., E. N. BROADBENT, P. J. OLIVEIRA, M. KELLER, D. E. KNAPP \& J. N. SILVA, 2006. Condition and fate of logged forests in the Brazilian Amazon. Proceedings of the National Academy of Sciences 103(34): 12947-12950. DOI: https://doi. org/10.1073/pnas.0604093103

ASNER, G. P., M. KELLER, M. LENTINI, F. MERRY \& C. SOUZA JR., 2009. Extração seletiva de madeira e sua relação com desmatamento. Amazonia and Global Change 186: 25-42. DOI: https://doi.org/10.1029/2008GM000723

ASSOCIAÇÃO VIROLA JATOBÁ (AVJ), 2015. Plano de Manejo Florestal Sustentável: Plano Operacional Anual do PDS Virola Jatobá - POA 06/2015. Associação Virola Jatobá do Projeto de Desenvolvimento Sustentável de Anapu, Anapu.

AZEVEDO-RAMOS, C., 2008. Sustainable development and challenging deforestation in the Brazilian Amazon: the good, the bad and the ugly. Unasylva 59(230): 12-16.
BARRETO, P., C. SOUZA JR., R. NOGUERÓN, A. ANDERSON \& R. SALOMÃO, 2006. Human pressure on the Brazilian Amazon forests: 1-84. World Resources Institute, Washington, DC.

BLANC, L., J. FERREIRA, M. G. PIKETTY, C. BOURGOIN, V. GOND, B. HÉRAULT, M. KANASHIRO, F. LAURENT, M. PIRAUX, E. RUTISHAUSER \& P. SIST, 2017. Managing degraded forests, a new priority in the Brazilian Amazon. Perspective (40): 1-4. DOI: http:// dx.doi.org/10.18167/agritrop/00042

BÖRNER, J., K. KIS-KATOS, J. HARGRAVE \& K. KÖNIG, 2015. Post-crackdown effectiveness of field-based forest law enforcement in the Brazilian Amazon. PLoS One 10(4): e0121544. DOI: https:// doi.org/10.1371/journal.pone.0121544

BRANCALION, P. H., D. R. D. ALMEIDA, E. VIDAL, P. G. MOLIN, V. E. SONTAG, S. E. SOUZA \& M. D. SCHULZE, 2018. Fake legal logging in the Brazilian Amazon. Science Advances 4(8): eaat1192. DOI: http://dx.doi.org/10.1126/sciadv.aat1192

BRASIL, 2012. Lei $n^{\circ}$. 12.727, de 17 de outubro de 2012. Altera a lei 12.651 , de 25 de maio de 2012. Diário Oficial da União, 18 out. 2012. Disponível em: http://www.planalto.gov.br/ccivil 03/ Ato2011-2014/2012/Lei/L12727.htm. Acesso em: 28 jan. $20 \overline{20}$.

BRAZ, E. M., M. D. OLIVEIRA, H. J. B. ARAÚJO \& E. M. MIRANDA, 1998. Plano de exploração sob critérios de manejo florestal de baixo impacto. EMBRAPA Acre-Circular Técnica (INFOTECA-E), Rio Branco.

BRINGEL, F. O. \& C. U. GONÇALVES, 2014. Territorialização camponesa e fronteira agrária - o caso do Projeto de Desenvolvimento Sustentável (PDS) Esperança, em Anapu-PA. Boletim Gaúcho de Geografia 41(2): 384-403.

CELENTANO, D., G. X. ROUSSEAU, F. H. MUNIZ, V. I. VAN DEURSEN, C. MARTINEZ, M. S. CARNEIRO, M. V. C. MIRANDA, M. N. R. BARROS, L. FREITAS, I. S. NARVAES, M. ADAMI, A. R. GOMES, J. C. RODRIGUES \& M. B. MARTINS, 2017. Towards zero deforestation and forest restoration in the Amazon region of Maranhão state, Brazil. Land Use Policy 68: 692-698. DOI: http:// dx.doi.org/10.1016/j.landusepol.2017.07.041

CELENTANO, D., M. V. MIRANDA, E. N. MENDONÇA, G. X. ROUSSEAU, F. H. MUNIZ, V. C. LOCH, V. I. VAN DEURSEN, L. FREITAS, P. ARAÚJO, I. S. NARVAES, M. ADAMI, A. R. GOMES, J. C. RODRIGUES, C. KAHWAGE, M. PINHEIRO \& M. B. MARTINS, 2018. Desmatamento, degradação e violência no" Mosaico Gurupi"A região mais ameaçada da Amazônia. Estudos Avançados 32(92): 315-339. DOI: https://doi.org/10.5935/0103-4014.20180021

CHANDER, G., B. L. MARKHAM \& J. A. BARSI, 2007. Revised Landsat-5 thematic mapper radiometric calibration. IEEE Geoscience and Remote Sensing Letters 4: 490-494. DOI: http:// dx.doi.org/10.1109/LGRS.2007.898285

CHIMELI, A. B. \& R. R. SOARES, 2017. The use of violence in illegal markets: evidence from mahogany trade in the Brazilian Amazon. American Economic Journal: Applied Economics 9(4): 30-57. DOI: http://dx.doi.org/10.1257/app.20160055

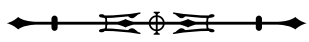


CONSELHO NACIONAL DO MEIO AMBIENTE (CONAMA), 2009. Resolução n. 406, de 02 de fevereiro de 2009. Estabelece parâmetros técnicos a serem adotados na elaboração, apresentação, avaliação técnica e execução de Plano de Manejo Florestal Sustentável - PMFS com fins madeireiros, para florestas nativas e suas formas de sucessão no bioma Amazônia. Diário Oficial da União, 06 fev. 2009. Disponível em: http://www2. $\mathrm{mma}$.gov.br/port/conama/legiabre.cfm?codlegi=597. Acesso em: 12 maio 2020.

DINIZ, C. G., A. A. SOUZA, D. C. SANTOS, M. C. DIAS, N. C. LUZ, D. R. V. MORAES, J. S. MAIA, A. R. GOMES, I. S. NARVAES, D. M. VALERIANO, L. E. P. MAURANO \& M. ADAMI, 2015. DETER-B: The new Amazon near real-time deforestation detection system. leee Journal of Selected Topics in Applied Earth Observations and Remote Sensing 8(7): 3619-3628. DOI: http://dx.doi.org/10.1109/ JSTARS.2015.2437075

FONSECA, L., F. PONZONI \& R. CARTAXO, 2004. Radiometric quality assessment of CBERS2. Instituto Nacional de Pesquisas Espaciais (Technical Report APPL-06-2004), São José dos Campos.

FRANCHI, T., M. BURSZTYN \& J. A. L. DRUMMOND, 2011. A questão ambiental e o adensamento da presença do Exército brasileiro na Amazônia Legal no final do século $X X$. Novos Cadernos NAEA 14(1): 21- 41. DOI: http://dx.doi.org/10.5801/ ncn.v14i1.597

GHAZOUL, J., Z. BURIVALOVA, J. GARCIA-ULLOA \& L. A. KING, 2015. Conceptualizing forest degradation. Trends in Ecology \& Evolution 30(10): 622-632. DOI: https://doi.org/10.1016/j. tree.2015.08.001

GONÇALVES, D. B., 2005. Desenvolvimento sustentável: o desafio da presente geração. Revista Espaço Acadêmico 51: 1-7.

GRECCHI, R. C., R. BEUCHLE, Y. E. SHIMABUKURO, L. E. ARAGÃO, E. ARAI, D. SIMONETTI \& F. ACHARD, 2017. An integrated remote sensing and GIS approach for monitoring areas affected by selective logging: a case study in northern Mato Grosso, Brazilian Amazon. International Journal of Applied Earth Observation and Geoinformation 61: 70-80. DOI: https://doi. org/10.1016/j.jag.2017.05.001

GREENPEACE, 2014. A crise silenciosa da Amazônia - Caso 5 Tecniflora LTDA. Disponível em: www.bibliotecadigital.abong.org. $\mathrm{br} /$ bitstream/handle/11465/1252/138. pdf?sequence=1. Acesso em: 23 abril 2019.

GUIMARÃES, U. S. \&A. R. GOMES, 2012. Detecção de exploração seletiva de madeira utilizando os satélites Landsat 5 TM e Resourcesat 1 Liss-3 em áreas de manejo florestal do leste do estado do Acre, Brasil. Anais do Symposium SELPLER 15: 1 CD-ROM.

GUTMAN, G., C. HUANG, G. CHANDER, P. NOOJIPADY \&J. G. MASEK, 2013. Assessment of the NASA-USGS Global Land Survey (GLS) datasets. Remote Sensing of Environment 134: 249-265. DOI: https://doi.org/10.1016/j.rse.2013.02.026
HUMPHRIES, S., T. P. HOLMES, K. KAINER, C. G. G. KOURY, E. CRUZ \& R. M. ROCHA, 2012. Are community-based forest enterprises in the tropics financially viable? Case studies from the Brazilian Amazon. Ecological Economics 77: 62-73. DOI: https:// doi.org/10.1016/j.ecolecon.2011.10.018

INSTITUTO BRASILEIRO DE PESQUISA DA AMAZÔNIA (IMAZON), 2020. Monitoramento da Amazônia. Disponível em: https://imazon.org.br/programas/monitoramento-da-amazonia/. Acesso em: 01 outubro 2020.

INSTITUTO NACIONAL DE COLONIZAÇÃO E REFORMA AGRÁRIA (INCRA), 1999. Portaria/INCRA/P/nº 477, de 04 de novembro de 1999. Trata da criação de Projeto de Desenvolvimento Sustentável. Disponível em: http://www.incra.gov.br/sites/default/ files/uploads/institucionall/legislacao--/portarias/portarias-de-1999/ portaria_incra_p477_041199.pdf. Acesso em: 27 junho 2018.

INSTITUTO NACIONAL DE COLONIZAÇÃO E REFORMA AGRÁRIA (INCRA), 2002a. Portaria n. 1.040, de 11 de dezembro de 2002. Dispõe sobre as alterações do Art. $3^{\circ}$ da Portaria INCRA/P/ $n^{\circ}$ 477/99, e dá outras providências. Diário Oficial da União, 12 dez. 2002. Disponível em: https://www.jusbrasil.com.br/diarios/ DOU/2002/12/12. Acesso em: 27 junho 2018.

INSTITUTO NACIONAL DE COLONIZAÇÃO E REFORMA AGRÁRIA (INCRA), 2002b. Portaria/INCRA/SR-01(G)/n . 39/2002, de 13 de novembro de 2002. Trata da criação de Projeto de Desenvolvimento Sustentável Virola Jatobá. Disponível em: http:// www.incra.gov.br/sites/default/files/uploads/institucionall/legislacao--/ portarias/portarias-de-2002/portaria incra p39 131102.pdf. Acesso em: 27 junho 2018.

INSTITUTO NACIONAL DE COLONIZAÇÃO E REFORMA AGRÁRIA (INCRA), 2010. Instrução Normativa/INCRA/n ${ }^{\circ} .65$, de 27 de dezembro de 2010. Estabelece critérios e procedimentos para as atividades de Manejo Florestal Sustentável em Projetos de Assentamento. Disponível em: http://www.incra.gov.br/sites/default/ files/uploads/legislacao/instrucao-normativa/in_65-2010_manejo florestal.pdf. Acesso em: 27 junho 2018.

INSTITUTO NACIONAL DE COLONIZAÇÃO E REFORMA AGRÁRIA (INCRA), 2018. Portaria/n $n^{\circ}$ 1.470, de 31 de agosto de 2018. Dispõe sobre a destinação do Lote 177 e Lote 180 da Gleba Belo Monte, e dá outras providências. Diário Oficial da União, 26 set. 2018. Disponível em: https://www.in.gov.br/materia/-/ asset publisher/Kujrw0TZC2Mb/content/id/42374196/do1-201809-26-portaria-n-1-470-de-31-de-agosto-de-2018-42373880. Acesso em: 7 julho 2019.

KOHLHEPP, G., 2002. Conflitos de interesse no ordenamento territorial da Amazônia brasileira. Estudos Avançados 16(45): 37-61. DOI: https://doi.org/10.1590/S0103-40142002000200004

LE TOURNEAU, F. M. \& M. BURSZTYN, 2010. Assentamentos rurais na Amazônia: contradições entre a política agrária e a política ambiental. Ambiente \& Sociedade 13(1): 111-130. DOI: https://doi. org/10.1590/S1414-753X2010000100008

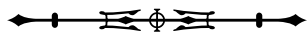


LIMA, T. A., R. BEUCHLE, A. LANGNER, R. C. GRECCHI, V. C. GRIESS \& F. ACHARD, 2019. Comparing Sentinel-2 MSI and Landsat $8 \mathrm{OLI}$ imagery for monitoring selective logging in the Brazilian Amazon. Remote Sensing 11(8): 961. DOI: https://doi. org/10.3390/rs11080961

MARQUES, G. S., 2013. SPVEA: o Estado na crise do desenvolvimento regional amazônico (1953-1966). Revista da Sociedade Brasileira de Economia Política 34: 163-198.

MATRICARDI, E. A., D. L., SKOLE, M. A. PEDLOWSKI \& W. CHOMENTOWSKI, 2013. Assessment of forest disturbances by selective logging and forest fires in the Brazilian Amazon using Landsat data. International Journal of Remote Sensing 34(4): 1057-1086. DOI: https://doi.org/10.1080/01431161.2012.717182

MELLO, N. G. R. D. \& P. ARTAXO, 2017. Evolução do plano de ação para prevenção e controle do desmatamento na Amazônia legal. Revista do Instituto de Estudos Brasileiros (66): 108-129. DOI: https://doi.org/10.11606/issn.2316-901x.v0i66p108-129

MENDES, J. \& N. M. PORRO, 2015. Conflitos sociais em tempos de ambientalismo: direito vivo à terra em assentamentos com enfoque conservacionista. Ambiente \& Sociedade 18(2): 97-114. DOI: https://doi.org/10.1590/1809-4422asocex06v1822015en

MORAN, E. F., 2016. Roads and dams: infrastructuredriven transformations in the brazilian amazon. Ambiente \& Sociedade 19(2): 207-220. DOI: https://doi.org/10.1590/18094422ASOC256V1922016

MUTTAQIN, M. Z., I. ALVIYA, M. LUGINA \& F. A. U. HAMDANI, 2019. Developing community-based forest ecosystem service management to reduce emissions from deforestation and forest degradation. Forest Policy and Economics 108: 101938. DOI: https://doi.org/10.1016/j.forpol.2019.05.024

OLIVEIRA, R. R. S., M. G. L. SILVA, I. S. NARVAES, T. F. CORDEIRO, D. M. VALERIANO, A. R. GOMES, M. ADAMI \& L. J. M. FREITAS, 2017. Detecção de padrões espaciais ligados à exploração florestal madeireira na Amazônia Legal: o caso da COOMFLONA, na Floresta Nacional do Tapajós. Anais do Simpósio Brasileiro de Sensoriamento Remoto - SBSR 18: 2216-2223.

PINHEIRO, T. F., M. I. S. ESCADA, D. M. VALERIANO, P. HOSTERT, F. GOLLNOW \& H. MÜLLER, 2016. Forest degradation associated with logging frontier expansion in the Amazon: the BR163 region in Southwestern Pará, Brazil. Earth Interactions 20(17): 1-26. DOI: http://dx.doi.org/10.1175/EI-D-15-0016.1

PORRO, R., N. S. M. PORRO, M. C. MENEZES \& O. BARTHOLDSON, 2015. Collective action and forest management: Institutional challenges for enhanced social-ecological systems of the environmental agrarian reform in Anapu, Brazilian Amazon. International Forestry Review 17(Supl. 1): 20-37. DOI: http:// dx.doi.org/10.1505/146554815814668990
PORRO, R., N. S. M. PORRO, O. D. S. WATRIN, H. D. N. ASSUNÇÃO \& S. JUNIOR, 2018. Implicações sociais, econômicas e ambientais de uma iniciativa de manejo florestal comunitário em assentamento na Amazônia Oriental. Revista de Economia e Sociologia Rural 56(4): 623-644. DOI: http://dx.doi. org/10.1590/1234-56781806-94790560405

PORRO, N. S. M., R. PORRO, M. TORRES \& D. P. P. BRAGA, 2020. Quem tem o “direito de dizer o direito" sobre um PDSProjeto de Desenvolvimento Sustentável?: 1-44. INEAF, Belém.

RAMOS, A. A., 2020. Influence of PPCDAM in combating deforestation in the Brazilian legal Amazon. Innovation \& Technological Development 1(1): 99-122.

RODRIGUES, T. E., R. C. SILVA, B. N. R. SILVA, J. M. L. SILVA, M. A. VALENTE, T. A. DARIVA, A. S. JESUS \& A. VENTURIERI, 2007. Caracterização, mapeamento e classificação dos solos da área de influência da BR-163 (Cuiabá- Santarém) e BR-230 (Transamazônica), no estado do Pará. In: A. VENTURIERI (Ed.): Zoneamento ecológico-enonômico da área de influência da BR-163 (Cuiabá - Santarém): v. 2: 403-573. EMBRAPA Amazônia Oriental, Belém.

SECRETARIA DE MEIO AMBIENTE E SUSTENTABILIDADE DO PARÁ (SEMAS-PA), 2014. Portaria $n^{\circ} .63 / 2014$. GAB/SEMA de 15 de janeiro de 2014. DOEPA no 32.563, de 16 jan. 2014, caderno 6, página 1. Disponível em: https://www.semas.pa.gov. br/2014/01/16/portaria-no-0632014-gabsema-de-15-de-janrirode-2014-publicada-no-doepa-no-32-563-de-16012014-caderno6-pagina-1/. Acesso em: 27 junho 2018.

SECRETARIA DE MEIO AMBIENTE E SUSTENTABILIDADE DO ESTADO DO PARÁ (SEMAS-PA), 2015a. Instrução Normativa 05, de 10 de setembro de 2015. Dispõe sobre procedimentos técnicos para elaboração, apresentação, execução e avaliação técnica de Plano de Manejo Florestal Sustentável - PMFS nas florestas nativas exploradas ou não e suas formas de sucessão no Estado do Pará, e dá outras providências. Disponível em: https:// www.semas.pa.gov.br/2015/09/11/in-05-de-10092015-publicadano-doe-32969-de-11092015-paginas-de-37-57/. Acesso em: 27 junho 2018.

SECRETARIA DE MEIO AMBIENTE E SUSTENTABILIDADE DO ESTADO DO PARÁ (SEMAS-PA), 2015b. Laudo Técnico n. 11155, de 1 de outubro de 2015. SEMAS-PA, Belém.

SHIMABUKURO, Y. E. \& J. A. SMITH, 1991. The leastsquares mixing models to generate fraction images derived from remote sensing multispectral data. IEEE Transactions on Geoscience and Remote Sensing 29(1): 16-20. DOI: https://doi. org/10.1109/36.103288

SHIMABUKURO, Y. E., J. R. SANTOS, A. R. FORMAGGIO, V. DUARTE \& B. F. T. RUDORFF, 2012. The Brazilian Amazon monitoring program: PRODES and DETER projects. In: F. ACHARD \& M. C. HANSEN (Ed.): Global forest monitoring from earth observation: 153-169. CRC Press, Boca Raton.

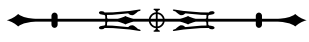


SHIMABUKURO, Y. E., R. BEUCHLE, R. C. GRECCHI \& F.ACHARD, 2014. Assessment of forest degradation in Brazilian Amazon due to selective logging and fires using time series of fraction images derived from Landsat ETM+ images. Remote Sensing Letters 5(9): 773782. DOI: https://doi.org/10.1080/2150704X.2014.967880

SHIMABUKURO, Y. E., E. ARAI, V. DUARTE, A. JORGE, E. G. D. SANTOS, K. A. C. GASPARINI \& A. C. DUTRA, 2019. Monitoring deforestation and forest degradation using multi-temporal fraction images derived from Landsat sensor data in the Brazilian Amazon. International Journal of Remote Sensing 40(14): 5475-5496. DOI: https://doi.org/10.1080/01431161.2019.1579943

SILVA, E., C. A. A. S. RIBEIRO, S. V. MARTINS \& N. T. SANTOS, 2009. Concessões de florestas públicas na Amazônia: desafios para uso sustentável dos recursos florestais. Bioikos 23(2): 91-102.

SOUZA, A. A. A., A. N. PONTES, M. ADAMI \& I. S. NARVAES, 2017. A contribuição das estradas e o padrão de desflorestamento e degradação da cobertura florestal no sudoeste paraense. Revista Brasileira de Cartografia 69(9): 1711-1724.

SOUZA JR., C. M., D. A. ROBERTS \& M. A. COCHRANE, 2005. Combining spectral and spatial information to map canopy damage from selective logging and forest fires. Remote Sensing of Environment 98(2-3): 329-343. DOI: http://dx.doi.org/10.1016/j. rse.2005.07.013
TRITSCH, I., P. SIST, I. S. NARVAES, L. MAZZEI, L. BLANC, C. BOURGOIN, C. GUILLAUME \& V. GOND, 2016. Multiple patterns of forest disturbance and logging shape forest landscapes in Paragominas, Brazil. Forests 7(12): 315. DOI: http://dx.doi. org/10.3390/77120315

UNITED STATES GEOLOGICAL SURVEY (USGS), [s. d.]. Disponível em: https://data.usgs.gov/datacatalog/. Acesso em: 7 julho 2019.

UNIVERSITY OF MARYLAND, 2000. Global land cover facility. A Landcover Earth Science Information Partnership, College Park.

WATRIN, O. D. S., T. M. D. SILVA, M. MOURÃO JR., R. PORRO \& A. P. BELLUZZO, 2020. Dinâmica do uso e cobertura da terra em Projeto de Desenvolvimento Sustentável na região da rodovia Transamazônica, Pará. Sociedade \& Natureza 32: 92-107. DOI: http://dx.doi.org/10.14393/SN-v32-2020-45146

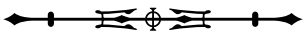

